scans there were positive signs suggestive of deep vein thrombosis. These signs consisted of calf pain, tenderness, or the sudden occurrence of oedema, and in seven cases there were two or more signs present (table II). Homan's sign and increased skin temperature were not found in any of these cases.

TABLE II-Physical Signs when Fibrinogen Test is Normal

\begin{tabular}{|c|c|c|c|c|c|}
\hline & Groups: & $\begin{array}{c}\text { Tubal } \\
\text { Ligation }\end{array}$ & $\begin{array}{c}\text { Caesarean } \\
\text { Section }\end{array}$ & $\begin{array}{l}\text { Age } 30 \\
\text { or more }\end{array}$ & \\
\hline $\begin{array}{l}\text { Pain + tenderness + oedema } \\
\text { Pain + tenderness/oedema } \\
\text { Oedema + tenderness } \\
\text { Oedema alone }\end{array}$ & $\begin{array}{l}\because \\
\cdots \\
\cdots\end{array}$ & $\begin{array}{l}0 \\
1 \\
0 \\
4\end{array}$ & $\begin{array}{l}0 \\
0 \\
1 \\
1\end{array}$ & $\begin{array}{l}2 \\
2 \\
1 \\
1\end{array}$ & $\begin{array}{l}2 \\
3 \\
2 \\
6\end{array}$ \\
\hline & Total & 5 & 2 & 6 & 13 \\
\hline
\end{tabular}

\section{Discussion}

This series shows that deep vein thrombosis is a rare event in the puerperium even in "high risk" cases. It also shows the fallacy of making a diagnosis of calf vein thrombosis on clinical signs alone. In this study signs were present in the calves of 13 women with normal ${ }^{125} \mathrm{I}$-labelled fibrinogen tests.

The incidence in this series is much lower than the insidence of occult thrombosis in general surgical cases. One reason for this may be age. The mean age for this series was 30.8 years (range 16-44 years) whereas surveys on surgical patients have generally dealt with patients over 40 years. Another factor may be the increased mobility of obstetric patients and the need to be up and caring for a child. This cannot be a predominant factor, however, because thrombosis is usually initiated during surgery (Flanc et al., 1968; Negus et al., 1969; Kakkar et al., 1970a).

Oestrogens were not given to any patient in this series and they have been stated to cause an increased incidence of thromboembolism in the puerperium (Daniel et al., 1967; Jeffcoate et al., 1968). It is interesting to note that Friend and Kakkar (1970) when using ${ }^{125} \mathrm{I}$-labelled fibrinogen and phlebography found three cases of deep vein thrombosis in 80 puerperal women who had all been given hexoestrol dipropionate to suppress lactation. The fact that the patients they reported had a mean age 5 years younger than those in this series and had had normal deliveries substantiates the fact that oestrogen predisposes to deep vein thrombosis.

${ }^{125}$ I-labelled fibrinogen provides an ideal screening method for the detection of leg vein thromtosis in high risk cases. Doppler ultrasound flow detection is simple and convenient but only reliable if occlusion of the major veins is present. It can be used during pregancy and in breast feeding mothers whereas the radioactive fibrinogen test cannot. The presence of alteration of the spontaneous flow sounds with respiration was variable and probably represented partial proximal venous occlusion from the enlarged uterus. Sigel et al. (1970) also stated that little reliance should be placed on spontaneous flow sounds, and it seems that only the presence of augmented flow sounds should be determined in routine screening.

The ${ }^{125} \mathrm{I}$-labelled fibrinogen test cannot be recommended for routine screening in the puerperium because of the low incidence of leg vein thrombosis. It is valuable in excluding thromboembolic disease in patients with signs suggestive of deep vein thrombosis, thus avoiding unnecessary anticoagulation. It is speculative as to what percentage of emboli arise from pelvic veins in obstetrics and the Doppler ultrasound is a practical way of screening for pelvic vein thrombosis.

I am particularly grateful to Dr. D. W. Warrell for his help and encouragement. I also thank Professor W. I. C. Morris and the consultant obstetricians at St. Mary's Hospital, Manchester, for allowing me to study patients under their care.

\section{References}

Browse, N. (1969). British Medical Gournal, 4, 676.

Daniel, D. G., Campbell, H., and Turnbull, A. C. (1967). Lancet, 2, 287.

Department of Health and Social Security (1972). Report on Confidential Enquiries into Maternal Deaths in England and Wales, 1967-1969. London, H.M.S.O.

Evans, D. S. (1970). British fournal of Surgery, 57, 726.

Flanc, C., Kakkar, V. V., and Clarke, M. B. (1968). British fournal of Surgery, 55, 742 .

Friend, J. R., and Kakkar, V. V. (1970). fournal of Obstetrics and Gynaecology of the British Commonwealth, 77, 820 .

Hall, C. M., and Clark, C. G. (1971). British fournal of Surgery, 58, 101.

Hobbs, J. T., and Davies, J. W. L. (1960). Lancet, 2, 134.

Jeffcoate, T. N. A., Miller, J., Roos, R. F., and Tindall, V. R. (1968). British Medical fournal, 4, 19.

Kakkar, V. V., Howe, C. T., Flanc, C., and Clarke, M. B. (1969). Lancet, 2, 230.

Kakkar, V. V., Howe, C. T., Nicolaides, A. N., Renney, J. T. G., and Clarke, M. B. (1970a). American fournal of Surgery, 120,527.

Kakkar, V. V., Nicolaides, A. N., Renny, J. T. G., Friend, J. R., and Clarke, M. B. (1970b). Lancet, 1, 540 .

Lambie, J. M. et al. (1970). British Medical Fournal, 2, 142

Negus, D., Pinto, D. J., and Brown, N. (1969). Lancet, 1, 220.

Negus, D., Pinto, D. J., LeQuesne, L. P., Brown, N., and Chapman, M. (1968). British fournal of Surgery, 55, 835 .

Pai, B. Y., and Negus, D. (1971). Lancet, 2, 1098.

Sigel, B. et al. (1970). Archives of Surgery, 100, 535.

Sigel, B. et al. (1970). Archives of Surgery,

Sigel, B. et al. (1968). Surgery, 64, 332 .

. American Fournal of Surgery, 113, 311.

Yao, S. T., Gourmos, C., and Hobbs, J. T. (1972). Lancet, $1,1$.

\title{
Hyperinfection Syndrome with Strongyloides Stercoralis in Malignant Lymphoma
}

\author{
MALCOLM ADAM， OWEN MORGAN， CLEMENT PERSAUD，WILLIAM N. GIBBS
}

British Medical fournal, 1973, 1, 264-266

\section{Summary}

Hyperinfection with Strongyloides stercoralis occurred in three patients with malignant lymphoma. The probable cause in each case was alteration of the immune responses

University of the West Indies, Kingston, Jamaica

MALCOLM ADAM, M.B., M.R.C.P., Lecturer, Department of Medicine OWEN MORGAN, M.D., M.R.C.P., Lecturer, Department of Medicine CLEMENT PERSAUD, M.SC., Resident Microbiologist

WILLIAM N. GIBBS, M.R.C.PATH., Lecturer, Department of Pathology either as a result of the malignant lymphoma or by the treatment given. Though thiabendazole (Mintezol) has produced reasonable results in the treatment of the hyperinfection syndrome, preliminary data suggest that the new broad-spectrum anthelmintic levamisole (Ketrax) is more effective. All patients who live or have lived in an area where strongyloidiasis is endemic should be investigated to detect the presence of the nematode before and during treatment with drugs with immunosuppressive properties. In view of the high mortality with S. stercoralis hyperinfection, vigorous therapy should be instituted before the use of immunosuppressive drugs. 


\section{Introduction}

Strongyloidiasis is a disease resulting from overwehelming infection with the parasitic nematode Strongyloides stercoralis. Although relatively common in the tropics, its distribution is worldwide. The clinical features as seen in Jamaica have already been reported by Bras et al. (1964). "Opportunistic" infection with organisms of low grade pathogenicity is well documented in diseases involving the reticuloendothelial system. In recent years, however, there have been sporadic reports of such parasitic infections with $S$. stercoralis.

The first case of strongyloidiasis with malignant lymphoma was described by Rogers and Nelson (1966). Since then, four other cases have been reported (Rivera et al., 1970; Yim et al., 1970). We report three further cases of the hyperinfection syndrome with $S$. stercoralis in malignant lymphoma and discuss the possible role of the immune system in this association.

\section{Case Reports}

CASE 1

A 22-year-old Jamaican Negro labourer was seen at the University Hospital of the West Indies in May 1969 with a complaint of abdominal pain, anorexia, weight loss, and diarrhoea of three months' duration. On examination he was mildly anaemic, blood pressure $90 / 50 \mathrm{~mm} \mathrm{Hg}$, pulse 102 and regular. The abdomen was distended and the liver was enlarged $5 \mathrm{~cm}$ below the right costal margin. There were a few small, mobile, non-tender nodes in the submandibular and inguinal regions. The haemoglobin was $10.3 \mathrm{~g} / 100 \mathrm{ml}$, packed cell volume $34 \%$, mean corpuscular haemoglobin concentration $30 \%$, white blood cells $8,300 / \mathrm{mm}^{3}$ (neutrophils $53 \%$, lymphocytes $35 \%$ monocytes $3 \%$, eosinophils $9 \%$ ). Sickle cell preparation was negative, serum iron and serum $\mathbf{B}_{12}$ were both normal. Total protein was $5.0 \mathrm{~g} / 100 \mathrm{ml}$ (albumin $2.9 \mathrm{~g} / 100 \mathrm{ml}$, globulin $2.1 \mathrm{~g} / 100 \mathrm{ml}$ ). Serum protein electrophoresis showed a decrease of all fractions. Chest $x$-ray picture showed nothing abnormal. Barium meal examination showed absence of mucosal folds, dilatation of the duodenal loop to the junction of the third and fourth part, and mucosal oedema. The radiological picture was consistent with that of strongyloidiasis. Examination of the stools showed numerous $S$. stercoralis larvae.

The patient was treated with thiabendazole $2 \mathrm{~g}$ daily for 10 days. He improved greatly and was discharged two weeks after admission with his stool free of strongyloides larvae.

He was readmitted four months later with a recurrence of his initial symptoms. On examination the striking findings were a pyrexia of $99.6^{\circ} \mathrm{F}\left(37.6^{\circ} \mathrm{C}\right)$ and a soft spleen $6 \mathrm{~cm}$ below the left costal margin. Blood cultures and stool cultures both produced good growths of Salmonella typhimurium, and stool examination showed abundant $S$. stercoralis larvae.

He was given a course of thiabendazole $(40 \mathrm{~g})$ over 15 days before his stools became clear. The septicaemia, which failed to respond to chloramphenicol, settled quickly on co-trimoxazole (Septrin) tablets 1 three times a day.

Ten days later he became pyrexial again. There was now evidence of abdominal para-aortic node enlargement. In addition, there were small rubbery non-tender nodes in his neck. Cervical lymph node biopsy showed features of a reticulum cell sarcoma. Cytotoxic therapy was started but before this became effective the patient died. At necropsy, there was widespread involvement of the reticulo endothelial system by the lymphomatous process. Histologically invasive filariform larvae were found throughout the small intestine and in the lungs, lymph nodes, and spleen.

\section{CASE 2}

A 27-year-old Jamaican Negro shoemaker was admitted to the University Hospital in July 1970 with a three-month complaint of weakness, lower abdominal pains, vomiting after meals, intermittent diarrhoea, and weight loss of more than $40 \mathrm{lb}(18 \mathrm{~kg})$.

On examination he was pale, thin, and wasted with a distended abdomen. There was no organomegaly or lymphadenopathy. The haemoglobin was $9.0 \mathrm{~g} / 100 \mathrm{ml}$, white blood cells $20,700 / \mathrm{mm}^{3}$ (neutrophils $29 \%$, lymphocytes $70 \%$, eosinophils $1 \%$ ), platelets $120,700 / \mathrm{mm}^{3}$. The peripheral blood film showed moderate hypochromia with distorted mononuclear cells which constituted $65 \%$ of the lymphocytic series. Bone marrow examination showed hypocellularity with pronounced hypoplasia of the erythroid elements. Eosinophil metamyelocytes were increased and many of the myeloid precursors contained vacuoles in the cytoplasm. The absence of the abnormal mononuclear cells from the marrow suggested that they were derived from another source and made the diagnosis of an underlying lymphoma a strong possibility.

Stool examination showed numerous strongyloides larvae. Radiological investigation of the gastrointestinal tract showed changes consistent with a diagnosis of strongyloidiasis (Louisy and Barton, 1971).

The patient was given a $15 \mathrm{~g}$ course of thiabendazole over 10 days and discharged. When seen six weeks later at the outpatient clinic he had regained his lost weight and the stools were free of parasites.

Over the period of observation as an outpatient it was noticed that the absolute number of at normal mononuclear cells rose progressively to $35,000 / \mathrm{mm}^{3}$, and a tender lobulated mass could be felt in the epigastrium. An exploratory laparotomy showed a large group of retroperitoneal nodes and widespread infiltration of the liver and spleen by tumour tissue. Lymph node biopsy at the time of laparotomy showed Hodgkin's disease of the mixed cellularity type. Combination therapy with nitrogen mustard, vincristine, prednisone, and procarbazine (M.O.P.P.) was instituted and after a full regimen of six courses he remained well and at work.

\section{CASE 3}

A 46-year-old Jamaican farmer presented to the University Hospital in May 1971 with weakness, weight loss, and night sweats of six weeks' duration. On admission he was thin, pale, and febrile. There was generalized lymphadenopathy, the liver was $4 \mathrm{~cm}$ below the right costal margin, and the spleen was $3 \mathrm{~cm}$ below the left costal margin. The haemoglobin was $8 \cdot 1 \mathrm{~g} / 100 \mathrm{ml}$, white blood cells $8,100 / \mathrm{mm}^{3}$ (neutrophils $66 \%$, lymphocytes $13 \%$, monocytes $14 \%$, eosinophils $7 \%$ ). The blood film was that of an iron deficiency anaemia. Lymph node biopsy established the diagnosis of Hodgkin's disease of the lymphocyte depleted type. The patient was treated with M.O.P.P. combination therapy and he improved, although he never attained a state of complete remission. His final admission was in November 1971, when he was brought to the casualty department febrile and debilitated. He was markedly anaemic and there was massive generalized lymphadenopathy. The haemoglobin was $6.5 \mathrm{~g} / 100 \mathrm{ml}$ and the white blood count was $12,500 / \mathrm{mm}^{3}$ with a predominance of polymorphs. Despite intensive measures the patient died shortly after admission.

At necropsy there was disseminated Hodgkin's disease. Unfortunately, a histological search was not made for $S$. stercoralis, but all stages, including invasive filariform larvae, were found in the luminal contents.

\section{Discussion}

The diagnosis of the hyperinfection syndrome was based on a combination of the clinical features and the presence of unusually large numbers of filariform larvae in the stools. Cases 1 and 2 had proved lymphoma, and the diagnosis of strongyloidiasis was made before the use of steroids or cytotoxic agents. These two cases represent the only patients in the literature who had no drug therapy before hyperinfection with $S$. stercoralis was diagnosed. Case 1 is of particular interest since he was found, in addition, to have necatoriasis and giardiasis. $\mathrm{He}$ also developed a Salm. typhimurium septicaemia which was treated effectively with co-trimoxazole. In case 3 the Hodgkin's disease was treated with M.O.P.P. combination therapy, and the strongyloides hyperinfection was not diagnosed until necropsy.

Anthelmintic treatment was also of interest in these patients. Cases 1 and 2 required courses of $40 \mathrm{~g}$ and $15 \mathrm{~g}$ of thiabendazole respectively to render their stools free of the nematode. Over the past three years we have found it necessary to use courses of this magnitude to achieve effective results. So far we have encountered no significant side effects. The dosage used by us is much higher than the recommended $25 \mathrm{mg} / \mathrm{kg}$ twice daily for two days.

At this centre, in-vivo experiments with dogs, in-vitro experi- 
Summary of Data on Patients with Lymphoma Associated with Strongyloides

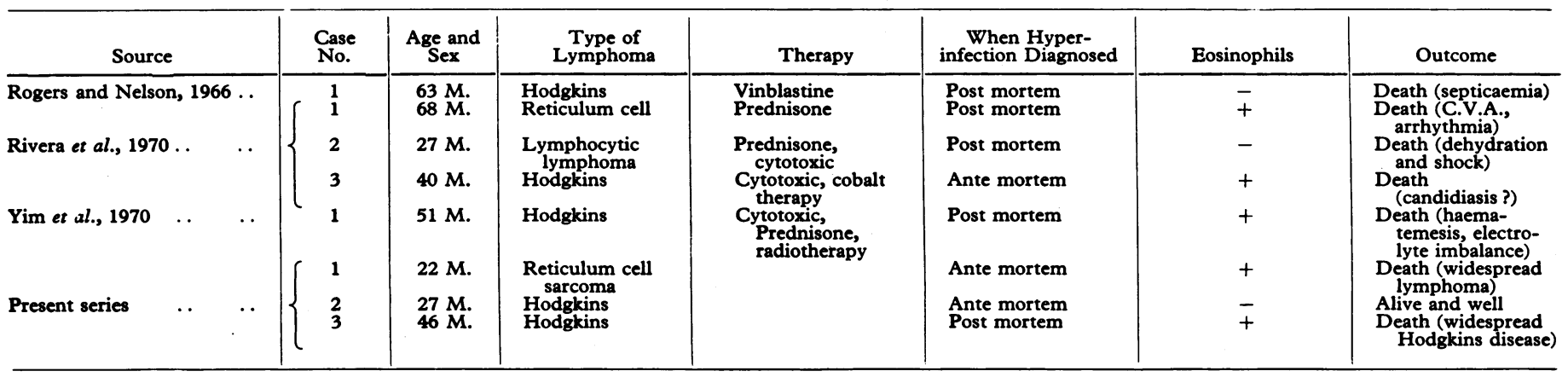

ments, and preliminary clinical trials with the broad-spectrum anthelmintic levamisole (Ketrax) (Persaud and Grant, 1972) indicate that it has significantly greater nematicidal activity than thiabendazole against $S$. stercoralis.

There was significant eosinophilia in cases 1 and 3 but not in case 2. As can be seen in the table, four of the five patients with eosinophilia died, but in only one case could severe strongyloidiasis be directly incriminated.

Eosinopenia in the hyperinfection syndrome has been thought to be a poor prognostic sign (Wilson and Thompson, 1964). Since eosinophilia occurs fairly frequently in Hodgkin's disease (Whitby and Britton, 1969) its presence in this association does not necessarily imply a good prognosis.

The nematode, under normal circumstances may exist in the gut without causing serious disability. However, should the hostparasite equilibrium be disturbed in favour of the parasite, the hyperinfection state may ensue. Recent evidence suggests that there is an uninhibited proliferation of adult worms in dogs treated with steroids (Galliard and Berdonneau, 1953; Persaud, 1972, unpublished data). Experiments using Nippostrongylus brasiliensis as an experimental model have shown a significantly higher worm recovery from the intestine of cortisone-treated rabbits (Harley and Gallicchio, 1970). Also, prednisolone suppresses the start of an acquired resistance in rats during an initial infection. A second infection in drug-treated rats produced an uninhibited development of worms and the expulsion from the intestine was completely inhibited (Ogilvie, 1965). Periwinkle alkaloids have toxic effects on the autonomic nervous system (Goodman and Gilman, 1970). The resulting effects on gastrointestinal motility may be partly to inhibit the expulsion of $S$. stercoralis, thereby allowing proliferation and initiation of the autoinfective cycle.

In the cases previously reported, all patients had been exposed to either a periwinkie alkaloid or prednisone with other cytotoxic drugs, which may have suppressed the immune system thereby altering the host-parasite equilibrium. Since in our first two cases no immunosuppressive agent was used before the development of the hyperinfection syndrome, it is likely that this resulted from a partial immunological paresis that is known to occur in lymphoma (Miller, 1962).

Now that immunosuppressive drugs are in routine use in the treatment of lymphoma, it is essential that all patients undergoing this form of therapy who have ever been resident, or still reside, in an endemic area should have careful investigation to detect this type of infection before starting therapy. It is advisable also that these patients should have their stools checked at periodic intervals during the treatment, as latent infection can become apparent only after the start of therapy. It is also important for a similar approach to be adopted in other types of immunologically disturbed states in view of the high mortality associated with hyperinfection with this nematode (Rivera et al., 1970). Indeed, a fatal case has been reported in Brazil of a patient receiving immunosuppressive therapy after renal transplantation (Fagundes et al., 1971).

It is recommended, therefore, that wherever possible all patients with $S$. stercoralis infection be energetically treated before the use of immunosuppressive drugs.

\section{References}

Bras, G., Richards, R. C., and Irvine, R. A. (1964). Lancet, 2, 1257. Fagundes, L. A., Busato, O., and Brentano, L. (1971). Lancet, 2, 439. Galliard, P. H., and Berdonneau, R. (1953). Annales de Parasitologie Humaine et Comparée, 28, 163.

Goodman, L. S., and Gilman, A. (1970). Pharmacological Basis of Therapeutics, 4th edn.,p. 1378. New York, Macmillan.

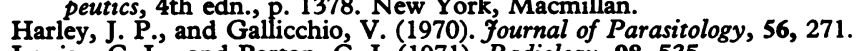

Louisy, C. L., and Barton, C. J. (1971). Radiology, 98, 535.

Miller, D. G. (1962). Annals of Internal Medicine, 57, 703.

Ogilvie, Bridget M. (1965). Parasitology, 55, 723.

Persaud, R. C., and Grant, L. S. (1972). Transactions of the Royal Society of Tropical Medicine, 56,368 .

Rivera, E., Maldonando, N., Velez-Garcia, E., Grillo, A. J., and Malant, G. (1970). Annals of Internal Medicine, 72, 199.

Rogers, W. A. jun., and Nelson, B. (1966). Fournal of the American Medical Association, 195, 685.

Whitby, L., and Britton, C. J. C. (1969). Disorders of the Blood, 10th edn., p. 85 . London, Churchill.

Wilson, S., and Thompson, A. F. (1964). Fournal of Pathology and Bacteriology, 87, 169.

Yim, Y., Kikkawa, Y., Tanowitz, H., and Wittner, M. (1970). Fournal of Tropical Medicine and Hygiene, 10, 245. 